\title{
Redigindo textos, assimilando a palavra do outro
}

Maria José Nóbrega, mestra em Filologia e Língua Portuguesa pela USP, é assessora da Secretaria Municipal de Educação de São Paulo, das revistas "Carta na Escola" e "Carta Fundamental" e coordenadora do curso de Pós-Graduação "Docência em Língua Portuguesa" do Instituto Superior de Educação Vera Cruz - ISE Vera Cruz.

Contato: mazenobrega@hotmail.com

\section{Resumo}

Sustentando a tese de que a autoria possa emergir de atividades que envolvam a paráfrase e, portanto, relativizando a ideia de uma autoria absoluta, porque o sujeito ao escrever opera com as restrições impostas pelos gêneros, o objetivo do artigo é demonstrar as possibilidades do trabalho com categorias didáticas para a produção de textos: transcrição, reprodução, decalque e autoria, como instrumentos para permitir que os alunos, efetivamente, se inscrevam na cultura letrada. Palavras-chave: produção de textos; transcrição; reprodução; decalque; autoria

\section{Abstract}

In our research we chose to observe and analyse classes that privilege text production, since we believe the possibility of authorship being able to emerge from activities involving paraphrase: one learns how to write through the reformulation of another one's text, through the assimilation of another one's speech. We relativize the idea of absolute authorship, since the subject, when writing, operates with constraints imposed by the genres. Our objective is to demonstrate the possibilities of working with didactic categories for text production: transcription, reproduction, adapted copy and authorship, used as instruments which enable the students to enter literate culture effectively. Keywords: memory and discourse, paraphrase, text production. 
Repetir, repetir - até ficar diferente.

Repetir é um dom do estilo.

Manoel de Barros ${ }^{1}$

Aprende-se a escrever "tocando a linguagem de ouvido" (Albano, 1990), isto é, assimilando textos de outros, interagindo com a linguagem. É por meio da convivência com textos de diversos gêneros que repetimos de memória, ou que reproduzimos histórias completando, adaptando, suprimindo, modificando quer o conteúdo temático, quer o estilo verbal, quer a construção composicional, ou que nos inscrevemos nessa cadeia, interagindo com os textos já produzidos e suscitando outros.

0 texto, além da "voz" de quem o produz, reflete no mínimo mais uma "voz": aquela a quem ele se dirige. Mas, ao produzir textos, necessariamente o enunciador recorre a uma das variedades da língua. Fala por meio de uma outra voz, a voz da "carne", a voz de sua condição social, que conforma o que a voz individual pode dizer, processo que Bakhtin chama de ventrilocução.

Desse modo, é possível compreender que o processo de apropriação dos diferentes gêneros - enquanto formas típicas de linguagem, que incluem uma expressão própria que lhe é inerente - se dá também por um processo de ventrilocução, no qual se incorporam outras vozes, palavras alheias, que vão aos poucos se convertendo em palavras "próprias".

Assim, não é possível tratar os processos de imitação como sendo puramente mecânicos. Se, numa perspectiva discursiva, reproduzir é sempre dizer outra coisa, do ponto de vista psicológico não podemos ignorar, como sustenta Vygotsky, que "uma pessoa só consegue imitar aquilo que está no seu nível de desenvolvimento" (Vygotsky, 1999, p.114).

Os textos das crianças vão mudando à medida que incorporam significados de outros textos, mudam ao "refletir" ou "refratar" uma crescente dialogicidade: há sempre outros textos, ainda que silenciados, no texto que se produz.

1. In 0 livro das ignorãças. Rio de Janeiro: Record, 1997, p. 11. 
Meserani, em 0 intertexto escolar: sobre leitura, aula e redação (1995), discutindo a respeito das taxionomias em uso no contexto escolar, constata que são basicamente a narração, a descrição e a dissertação que principalmente orientam a produção escrita. Levando em conta a intimidade que há entre os textos que se leem e as propostas para redação, o autor propõe que se considerem três tipos de textos: a reprodução, a paráfrase e a criação, assim caracterizados: "um diálogo de vozes idênticas que se repetem como eco (reproduções), de vozes semelhantes (paráfrases) e de vozes diferentes e divergentes (criações)" (Meserani, 1995, p. 23).

Em meu trabalho, tendo a considerar tanto a reprodução como a paráfrase não como tipos de texto, mas como processos que podem estar presentes na atividade de produção do sujeito, podendo, do ponto de vista didático, funcionar como ferramentas para ensinar e aprender a redigir os diversos gêneros tais como circulam socialmente. É possível reproduzir uma notícia ou um conto, transcrever uma receita, parodiar uma canção ou uma propaganda, parafrasear um artigo etc.

Para que as categorias didáticas sugeridas para o trabalho com a produção de textos possam assegurar bons resultados, é importante uma análise cuidadosa do texto-modelo e das características do gênero em que se inscreve, de maneira a poder avaliar o texto que a criança produz de modo a identificar o que ela já sabe e o que ainda precisa aprender. A resposta a estas questões é fundamental para orientar o trabalho a ser desenvolvido.

Além disso, é importante ler cuidadosamente o texto do aluno, não para corrigi-lo, mas para interpretá-lo e para, confrontando-o com o texto-modelo, observar algumas marcas da atividade de produção do sujeito: o que foi acrescentado, o que foi omitido, o que foi invertido, o que foi substituído. Mais do que orientar uma pauta de refacção e de revisão do texto, identificar as passagens em que houve acréscimo, omissão, inversão ou substituição é uma atividade de interpretação. Que efeitos de sentido provocam os deslocamentos ou deslizes? Há interpretações conflitantes entre as diversas versões produzidas? Como essas interpretações apresentadas pelo novo texto exigem novas leituras do texto-modelo?

As atividades de leitura e de produção de textos planejadas para o trabalho escolar ao longo das séries iniciais do Ensino Fundamental devem procurar ampliar a competência discursiva dos alunos para o diálogo entre os textos. 
Para permitir a apropriação das especifidades dos diversos gêneros, procurou-se operar, didaticamente, com as seguintes categorias de produção de textos: transcrição, reprodução, decalque e autoria, conforme o quadro a seguir:

\begin{tabular}{|c|c|c|}
\hline $\begin{array}{c}\text { Categorias didáticas } \\
\text { para a prática de } \\
\text { produção de texto }\end{array}$ & $\begin{array}{c}\text { Conteúdo temático } \\
\text { (o que dizer) }\end{array}$ & $\begin{array}{c}\text { Construção } \\
\text { composicional / } \\
\text { estilo verbal } \\
\text { (como dizer) }\end{array}$ \\
\hline Transcrição & & \\
\hline Reprodução & & \\
\hline Decalque & & \\
\hline Autoria & & \\
\hline
\end{tabular}

As categorias propostas para ensinar a produzir textos permitem que, de diferentes formas, os alunos construam referências sobre os gêneros, apropriando-se das estruturas composicionais, do universo temático e estilístico dos textos que transcrevem, reproduzem, imitam. Aprendendo a reformular as palavras do outro, o aluno aprende os processos de autorreformulação que caracterizam o trabalho do escritor, ao elaborar tanto o conteúdo como a expressão, reformulando pela simples refacção de passagens ou pela alteração total.

\section{Atividades de transcrição}

Atividades de transcrição exigem do aluno que as realiza fidelidade ao registro, controle do que já foi escrito e do que ainda falta escrever, observação dos aspectos relacionados à segmentação do texto escrito e atenção às questões colocadas pela compreensão quer do sistema alfabético, quer das convenções do sistema ortográfico: o que dizer e o como dizer já estão determinados pelo texto original.

A tarefa de transcrever parece simples e talvez provoque alguma dúvida incluí-la como uma categoria de produção. Inicialmente, uma ressalva. Não se trata de uma cópia no sentido da prática escolar tradicional. A criança sabe o texto de cor ou, então, conta com uma gravação do texto, não tem nenhum registro escrito a que possa recorrer. Como os alunos das séries iniciais não dominam ainda as convenções próprias da língua escrita, a tarefa envolve um número razoável de dificuldades. 


\section{Análise da transcrição de um trava-língua²}

\author{
OTEIPO \\ OTEIPO PEGUTO AO TEIPO \\ CATO TEIPO O TEIPO O TEIPO TEI \\ O TEIPO RESIPOUDU AO TEIPO \\ QO TEIPO TEI TEIPO O TEIPO TEI \\ BRUNA
}

Vejamos, inicialmente, o que Bruna já sabe. Sua escrita já é praticamente alfabética, isto é, ela já sabe que as letras representam as unidades sonoras da língua. Em algumas soluções, ainda emprega o nome da letra representando, simultaneamente, o valor sonoro de duas unidades sonoras como em "RESIPOUDU" e "QO". Mesmo que em algumas ocorrências não o faça, praticamente já aprendeu que a escrita segmenta o texto em palavras. Mostra uma preocupação com a apresentação visual do texto em função do gênero, mudando de linha ao final de cada verso.

Ao confrontarmos a versão de Bruna com o texto-modelo, veremos que, no segundo verso, Bruna acrescenta "O TEIPO" e, no verso final, omite "TANTO" (Que o tempo tem tanto tempo / QO TEIPO TEI TEIPO), e omite também "QUANTO TEMPO" (Quanto tempo o tempo tem / O TEIPO TEI).

Por que tais acréscimos e omissões ocorrem? Algumas hipóteses são possíveis. Uma primeira diz respeito às características do gênero: trata-se de um jogo oral que tem por finalidade criar dificuldades para a articulação em voz alta, sendo composto pela repetição de palavras que exploram a aliteração. Bruna pode ter tido dificuldades para controlar o que já tinha escrito e o que faltava escrever porque os enunciados são muito parecidos. Mas essa dificuldade revela que Bruna não domina ainda os procedimentos de revisão próprios da escrita: se tivesse relido, durante a produção ou depois de ter concluído a tarefa, com certeza não teria dificuldades para riscar o que escreveu a mais e completar o que ficou faltando.

\section{Atividades de reprodução}

Atividades de reprodução permitem que o aluno fique, em parte, liberado da tarefa de determinar o conteúdo temático e a construção composicional já definidos pelo texto-modelo.
2. 0 texto, que me foi apresentado como subsídio para a preparação de uma reunião sobre perspectivas para o trabalho com a ortografia, é de uma criança da Educação Infantil da Fundação Bradesco em São Paulo. 
A tarefa oferece possibilidade de priorizar aspectos estilísticos característicos do plano da expressão do gênero a que pertence o texto-modelo, explorando uma série de aspectos relativos à construção da textualidade:

- operações de coesão (os processos anafóricos, os esquemas temporais);

- operações de conexão e de segmentação do texto (operadores temporais, lógicos e argumentativos; processos de coordenação e de subordinação; paragrafação);

- operações de modalização (asserção/negaação, apelo intersubjetivo, avaliação e apreciação).

Reproduzindo textos, a criança assimila, progressivamente, os padrões próprios da escrita: fala-se em uma "língua", mas escreve-se em "outra". Para que a atividade cumpra sua finalidade, isto é, permitir que o aluno amplie seu repertório expressivo e sua competência para selecionar, em função da situação comunicativa, a forma mais adequada, é importante que o texto-modelo ofereça alguma complexidade para que a paráfrase represente algum desafio. Se o texto é bastante sintético, apresenta um léxico próximo do uso em situações cotidianas, o que a criança pode aprender com o exercício?

\section{Análise da reprodução de um conto tradicional ${ }^{3}$}

OS 3 PORQUINHOS

ELES CISPALIARIÃO PRATICO FEIS UMA

CASA DE TIJOLO E EITOR FEIZ UMA CASA

DE MADEIRA E SISERO FEIS UMA CASA DE

PALIA E NOMEIO NA FLORESTA ESITIA

UM LOBOMAU NA FLORESTA E 3 PORQUI-

NHOS E O LOBOMAU FALOU POQUINHO

ABRA ÉSA POTA EU NÃO ABRU NEIN PELUS

LABIUS DU MEQUEISO INTANU EU VOU

ASOPRAR FFF EITOR EITOR OQUIÉ O LOBO

QUÉ MIPEGA ABRA ÉSA PORTA PORQUINHOS

AGENTE NÃO ABRO NEIN PELOS LABIUS DU

MEQUESO NITÃO EU VOA SPRA FFF

PRÁTICO PRATICO OQUI U LOBO QUÉ NUS

PEGA ABRA A PORTA PORQUINHOS A GENTA
3. 0 texto fez parte da avaliação diagnóstica de uma turma da $1^{a}$ série do Ensino Fundamental da Escola Utta/São Paulo, que era uma das escolas que integravam o programa de formação de professores desenvolvido pelo IPBA, em que atuava como coordenadora. 


\section{NÃO ABRI PELUSLABIUS DU NOSO QUESO}

FFF FFFFF FFFFFFFFFFFFF

EU VOU I PELA SNMINÉ EU

VOU COLOCA UMA BASIA NA SNMINÉ

AU AU AU AU XXXX FIM

ANDREAS

Andreas, quando produziu este texto, estava iniciando a $1^{\text {a }}$. série do Ensino Fundamental. Como Bruna, já dominava a base alfabética da língua, mas há indicações em sua escrita da observação que faz de outros sinais além das letras: o acento agudo, que usa sobre o "e" aberto; o hífen para marcar a separação de palavra, ao mudar de linha e o afastamento da margem, indicador de abertura de parágrafo, apenas no início do texto. Andreas realizou essas descobertas nos contatos que teve com o texto escrito, porque, até o momento em que a avaliação diagnóstica havia sido produzida, não tinha recebido instruções formais sobre o assunto.

Ao começar sua história, Andreas, contrariamente às restrições ao gênero, omite o segmento responsável pela orientação: quem são as personagens, onde e quando se passa a história. 0 emprego do pronome "ELES" pode sugerir que Andreas toma o título como fazendo parte do corpo do texto, mas sem dúvida a própria seleção de "CISPALIARIÃO" cria o pressuposto de que os porquinhos estavam juntos e de que algo motivou a decisão de cada um ir para um canto.

Andreas já dá mostras de começar a diferenciar a modalidade oral da escrita: emprega pronomes átonos "U LOBO QUÉ NUS PEGA", faz uso do diálogo, empregando verbos dicendi "E 0 LOBOMAU FALOU".

Ao ler a versão de Andreas e a de algumas outras crianças da classe, chamou-nos atenção o acréscimo da frase que funciona, estilisticamente, como um mote presente na resposta que os porquinhos dão ao lobo "EU NÃO ABRU NEIN PELUS LABIUS DU MEQUEISO", que não fazia parte do texto que a professora havia lido nem de nenhuma outra versão que conhecêssemos. A frase, que aparecia em algumas reproduções, nunca do mesmo modo, descobrimos ser "pelas barbas do meu queixo", que as crianças conheciam de uma adaptação inglesa para TV que na época era transmitida pela TV Cultura de São Paulo. A presença da frase produzia um efeito estético que apreciavam muito, apesar ou por causa do non-sense de lábios no queixo e de outros deslizes anatômicos. 
0 cruzamento da linguagem escrita com a da TV que aparece no texto de Andreas pode explicar as diversas omissões na narração do trecho final "EU VOU I PELA SNMINÉ EU VOU COLOCA UMA BASIA NA SNMINÉ AU AU AU AU XXXX FIM". As personagens descrevem em voz alta as ações que vão fazer ou fazem e as onomatopeias se encarregam dos efeitos especiais do lobo sendo fritado na bacia que o aguardava; mais televisivo impossível.

\section{Atividades de decalque}

Atividades de decalque funcionam quase como modelos lacunados: as questões formais já estão em parte definidas pelo caráter convencional da organização composicional e estilística dos gêneros, o que permite ao aluno concentrar-se no conteúdo temático.

$\mathrm{Na}$ atividade da criança, imitar um texto ganha contornos lúdicos, é um jogo, uma brincadeira em si. É como um quebra- cabeça que precisa ser montado: encaixam-se as peças muitas vezes sem o apoio da figura. A propósito, Vygotsky dizia que: "Numa criança em idade escolar, inicialmente a ação predomina sobre o significado e não é completamente compreendida. A criança é capaz de fazer mais do que ela pode compreender" (Vygotsky, 1999: 131).

Não é qualquer gênero que permite um bom aproveitamento para a realização de atividades de decalque. Canções, poemas que exploram estilisticamente a repetição e o paralelismo sintático são os que mais se ajustam à tarefa.

\section{Análise do decalque de um poema}

$\begin{array}{ll}\text { Às vezes de noite - } 1 & \text { Às vezes à noite - } 2 \\ \text { Às vezes, de noite, } & \text { Às veseses de noite } \\ \text { Acordo com muito medo } & \text { sinto uma lus encostando en min, } \\ \text { de alguém roubar os meus } & \text { que eu tenho que acordar. } \\ \text { segredos, } & \text { Para dizer que eu tenho que ficar } \\ \text { às vezes, de noite. } & \text { mais velho] } \\ & \text { Às vezes à noite } \\ \text { Às vezes, de noite, } & \text { Demora para agente fazer } \\ \text { adormeço e no lume da vela } & \text { amizade com o dia. }\end{array}$


estou desperta e mais velha

às vezes, de noite.

Às vezes, de noite,

no meu sonho corre um rio

que me faz tremer de frio,

às vezes, de noite.

Às vezes, de noite,

me digo que sou boa, que sou meiga

e que sou bela.]

E cresci. E estou cega.

Às vezes, de noite.
E a noite não dá porque

ela é qulta de mais.

Às vezes à noite

Da uma sensação que agente

está flutuando, vuando

e agente não sente nada.

Às vezes à noite

sinto que sou uma

pessoa livre de tudo

Às vezes à noite

Tenho pressão que sou um astro nalta

(grifos nossos)

Após a leitura do poema de Caparelli, a professora propõe às crianças escrever um poema parecido, mas dizendo o que se passa com elas "às vezes de noite".

Em seu poema, Felipe trata a noite como espaço de evasão e, quanto mais isso se explicita no texto, mais Luís Felipe se afasta do modelo, abandona a estratégia de preenchimento e envolve-se num projeto de autoria. Felipe é uma criança com problemas de desempenho escolar, mas produz um poema encantador em que expressa sua dificuldade de crescer e seu desejo de ser um "astro nalta", um astro navegador.

Normalmente as crianças elaboram bons textos quando desafiadas a produzir decalques de poemas desse tipo: o mote assegura a coerência interna dos elementos justapostos. Felipe foi além, conseguindo estabelecer coesão entre os elementos.

\section{Atividades de autoria}

As atividades de autoria exigem que o sujeito opere com as restrições impostas pelos gêneros: tanto em relação ao conteúdo temático - o que dizer - quanto em relação à organização composicional e ao plano expressivo/estilístico - como dizer.

Da mesma forma que sustentamos que a autoria pode emergir de atividades que envolvam paráfrase, sustentamos, também, que a autoria absoluta não existe. Escrevemos a partir das restrições impostas pelo gênero e fazemos, ainda que nos "esqueçamos", uso de palavras alheias. 
Se as atividades de paráfrase são práticas que objetivam permitir ao aluno ir assimilando as propriedades dos gêneros e aprendendo as convenções da língua escrita, é importante que tais atividades sejam acompanhadas da produção de textos de autoria, para que o professor possa avaliar o que dos gêneros estudados já foi assimilado e o que ainda precisa ser aprofundado.

0 texto de autoria revela o "nível de desenvolvimento real" do aluno. Sob pena de graves decepções, não podemos achar que as características encontradas em um texto de reprodução são as mesmas que serão encontradas em um texto de autoria. 0 texto-modelo funciona como um instrumento mediador, que fornece pistas, aponta caminhos. A produção final aponta 0 "nível de desenvolvimento potencial", aquele que é possível ser atingido com colaboração, em nosso caso, do texto-modelo. Em nossas análises de textos infantis, observamos, por exemplo, que o número de falhas ortográficas é consideravelmente maior em textos de autoria do que em textos que envolvam paráfrase. Há, sem dúvida, muito mais aspectos envolvidos e a tarefa do sujeito é, por sua vez, muito mais complexa.

\section{Análise da criação de um conto de fada ${ }^{4}$}

TÍTULO: PRINCESA E O PRINCIPI

HAVIA EM UMA MONTA NHA ENCANTADA

UMA MOSA MUITO BONITA TRABALIA MUITO

MAIS NÃO SABIA QUE SUA MAI ÉRRA UMA

RAINIA FICOU MUITO FELIS SABEDO QUE ÉRA

UMA PRINCESA UMA BELA TARDE MUITO BONITO

ÊM COM TRO UM PRINCIPI MUITO BONITO QUERIA

CE CASA CON PRINCIPI FOI DAI QUE A PRINCESA

CON QUIS TON O CEU DITINO FOI PARA PETO

DO PRINCIPI UA HARO BEJO A SUA BOCA

O PRINCIPI A DORO O BEJO QUE A PRINCESA

PIDIO O PRINCIPI EM CASA MENTO O PRINCIPI

A CENTO O CASA MENTO UM DIA FOI O CASA

MENTO MUITO LEHAO E MUITO DOCES E MUITA

ROSA VERMELAS E O PRINCIPI E A PRINCESA VIVERO

FELIS PARA CENPE

4. 0 texto faz parte de um conjunto apresentado como subsídio para a preparação de uma reunião sobre perspectivas para o trabalho com a ortografia, e é de uma criança da Educação Infantil da Fundação Bradesco em São Paulo. 
0 desafio - produzir um conto de fadas - foi feito às crianças depois de um trabalho bastante intenso com o gênero: ouviram muitas histórias, reproduziram oralmente e por escrito algumas delas.

De modo geral, a leitura dos textos de autoria produzidos pelas crianças nos convida, além de apreciar a trama que cada criança cria, a localizar as vozes dos outros textos atualizados pelas escolhas que o autor realiza.

Com relação ao conteúdo temático, o texto, além da própria seleção de personagens, reproduz uma série de motivos clássicos do conto de fadas: a descoberta da identidade, o casamento. Com relação à estrutura composicional, o começo, ao introduzir a personagem em um lugar encantado, e o desfecho com a clássica forma do "e viveram felizes para sempre" marcam a adesão ao gênero. Do ponto de vista estilístico, há uma série de empregos que, seguramente, não fazem parte dos usos cotidianos da linguagem de uma criança de 6 anos: "MONTA NHA ENCANTADA", "FICOU MUITO FELIS SABEDO QUE ÉRA UMA PRINCESA", "FOI DAÍ QUE A PRINCESA CON QUIS TON O CEU DITINO", "FOI PARA PETO DO PRINCIPI U HARO".

Mas concorrem para a produção da história dessa princesa outros discursos que atestam a contemporaneidade da pequena autora que tenta escrever como Grimm. Sua personagem não atua como as princesas das narrativas tradicionais: toma iniciativas, quer se casar e vai à luta, agarra o príncipe e o beija, pede-o em casamento, é uma princesa que mais se parece com o modelo politicamente correto das adaptações mais recentes dos Estúdios Disney, que as crianças conhecem, na maioria das vezes, antes mesmo do original escrito, ou com as heroínas das novelas de TV a que as crianças assistem.

"É de acordo com nosso domínio dos gêneros que usamos com desembaraço que descobrimos mais depressa e melhor nossa individualidade neles" (Bakhtin, 1997, p. 304). Dessa forma, tornando suas as palavras do outro, durante as atividades de transcrição, reprodução, decalque e autoria espera-se que, ao longo da escolaridade, cada aluno desenvolva a autoria e, com ela, seu próprio estilo. 


\section{REFERÊNCIAS}

ABAURRE, M. B.; FIAD, R. S. e MAYRINK-SABINSON, M. L. T. Cenas de aquisição da escrita: o sujeito e o trabalho com o texto. Campinas: ALB e Mercado de Letras, 1997.

ALBANO, E. C. Da fala à linguagem tocando de ouvido. São Paulo: Martins Fontes, 1990.

BAKHTIN, M. Estética da criação verbal. São Paulo: Martins Fontes, 1997. Marxismo e filosofia da linguagem. São Paulo: Hucitec, 1992.

BRASIL. MINISTÉRIO DA EDUCAÇÃO. Parâmetros Curriculares de Língua Portuguesa: $1^{\circ}$ e $2^{\circ}$ ciclos. Brasília, 1997.

BRASIL. MINISTÉRIO DA EDUCAÇÃO. Parâmetros Curriculares de Língua Portuguesa: $3^{\circ}$ e $4^{\circ}$ ciclos. Brasília, 1998.

BRONCKART, J. P. Atividade de linguagem, textos e discursos: por um interacionismo sócio-discursivo. São Paulo: EDUC, 1999.

FRANÇOIS, F. Práticas do oral. Carapicuíba: Pré-Fono Departamento Editorial, 1996.

GERALDI, J. W. (org.) O texto na sala de aula: leitura e produção. Cascavel: ASSOESTE, 1984. Portos de Passagem. São Paulo: Martins Fontes, 1993. Linguagem e Ensino: exercícios de militância e divulgação. Campinas: ALB e Mercado de Letras, 1996.

JESUS, C. A. Reescrita: para além da higienização. Dissertação de Mestrado. Campinas: IEL/UNICAMP, 1995.

KLEIMAN, A. B. (org.). Os significados do letramento: uma nova perspectiva sobre a prática social da escrita. Campinas: Mercado de Letras, 1995.

KOCH, I. V. A inter-ação pela linguagem. São Paulo: Contexto, 1992.

MAINGUENEAU, D. Genèses du discours. Bruxelles: Pierre Mardaga Editeur, 1984.

Pragmática para o discurso literário.Tradução: M. Appenzeller. São Paulo: Martins Fontes, 1996. 
MESERANI, S. O intertexto escolar: sobre leitura, aula e redação. São Paulo: Cortez, 1995.

NÓBREGA, M. J. Paráfrase, autoria e processos de assimilação da palavra do outro. Dissertação de Mestrado. Programa de Pós-Graduação em Filologia e Língua Portuguesa, USP/FFLCH/DLCV, 2000.

ORLANDI, E P. (org.) Interpretação: autoria, leitura e efeitos do trabalho simbólico. Petrópolis: Vozes, 1996.

POSSENTI, S. Discurso, estilo e subjetividade. São Paulo: Martins Fontes, 1988.

O eu no discurso do outro ou a subjetividade mostrada. In ALFA

- Revista de Linguística. São Paulo: Ed. Unesp, 1995.

SANT'AnNA, A. R. Paródia, paráfrase \& Cia. São Paulo: Ática, 1985.

SERAFINI, M. T. Como escrever textos. São Paulo: Globo, 1989.

SOARES, M. Linguagem e escola: uma perspectiva social. São Paulo: Ática, 1986.

Letramento: um tema em três g'êneros. Belo Horizonte:

Autêntica, 1998.

VYGOTSKY, L. S. A Formação Social da Mente. São Paulo: Martins Fontes, 1999.

Pensamento e linguagem. São Paulo: Martins Fontes, 1996.

WERTSCH, J. V. Voces de la mente: un enfoque socio-cultural para el estudio de la acción mediada. Madrid: Visor Distribuciones, 1993.

WITTGENSTEIN, L. Investigações filosóficas. São Paulo: Abril Cultural, 1979.

\section{(Footnotes)}

1. 0 poema de Sérgio Caparelli integra a obra Restos de Arco-Íris. Porto Alegre, L\&PM, 1997, p. 58.

2. Poema produzido com base no original de Sérgio Caparelli pelo aluno Luís Felipe, na época cursando a $2^{\text {a }}$. série do Ensino Fundamental, no Colégio Humboldt, em São Paulo. 